Abstracta Iranica

Revue bibliographique pour le domaine irano-aryen

Volume 32-33 | 2013

Comptes rendus des publications de 2009-2010

\title{
Homa Katouzian. The Persians. Ancient, Mediaeval and Modern Iran
}

\section{Clément Therme}

\section{OpenEdition}

1 Journals

\section{Édition électronique}

URL : http://journals.openedition.org/abstractairanica/40145

DOI : 10.4000/abstractairanica.40145

ISSN : 1961-960X

Éditeur :

CNRS (UMR 7528 Mondes iraniens et indiens), Éditions de l'IFRI

\section{Édition imprimée}

Date de publication : 1 décembre 2013

ISSN : 0240-8910

Référence électronique

Clément Therme, "Homa Katouzian. The Persians. Ancient, Mediaeval and Modern Iran », Abstracta Iranica [En ligne], Volume 32-33 | 2013, document 214, mis en ligne le 01 juillet 2016, consulté le 28 septembre 2020. URL : http://journals.openedition.org/abstractairanica/40145 ; DOI : https://doi.org/ 10.4000/abstractairanica.40145

Ce document a été généré automatiquement le 28 septembre 2020.

Tous droits réservés 


\title{
Homa Katouzian. The Persians. Ancient, Mediaeval and Modern Iran
}

\author{
Clément Therme
}

\section{RÉFÉRENCE}

Homa Katouzian. The Persians. Ancient, Mediaeval and Modern Iran. New Haven/London, Yale University Press, 2009, 452 p.

1 L'A. réussit la gageure de présenter de manière rigoureuse et concise l'histoire millénaire de l'Iran depuis la naissance de l'Empire Perse jusqu'à nos jours. Les choix méthodologiques de Katouzian, qui ne se limite pas à une description factuelle de l'histoire iranienne, sont l'une des principales qualités de l'ouvrage. Le lecteur bénéficie ainsi de la connaissance approfondie des faits constitutifs de l'histoire iranienne de l'A., qui ne néglige pas pour autant la dimension analytique. A titre d'illustration, l'A. développe une approche comparée de l'histoire iranienne et européenne pour la période contemporaine, il n'hésite également pas à proposer une grille de lecture originale décrivant, de manière globale, les relations entre l'Etat et la société en Iran.

2 Cet ouvrage de référence offre au lecteur une somme d'érudition considérable concernant l'histoire mais aussi la société et la culture iraniennes en restant accessible au non-spécialiste. Cet ouvrage est indispensable pour tous ceux qui souhaitent comprendre l'Iran contemporain et, plus particulièrement, la quête d'indépendance d'un pays qui n'a certes jamais été directement colonisé, mais dont l'indépendance n'a été que partielle tout au long du XIX ${ }^{\mathrm{e}}$ siècle. Cette profondeur historique permet à l'auteur d'expliciter les forces profondes à l'œuvre au moment de la révolution de 1979. La révolution iranienne ne correspond pas aux modèles révolutionnaires russe et français. C'est en raison de ce prisme comparatiste que se sont développées, en Occident, des perceptions biaisées avec, en particulier, une sous-estimation par les analystes de la dimension antioccidentale de la révolution islamique. L'A. conclut en constatant la crise d'autorité et de légitimité que traverse la République islamique, 
depuis les élections présidentielles, contestées, de juin 2009. Il note que ces élections constituent un tournant majeur dans l'histoire de la République islamique. A cette occasion, ce n'est certes pas la quasi-totalité de la population qui s'est exprimée contre le régime, comme en 1979, mais la fracture entre l'Etat et l'opinion publique semble aujourd'hui plus profonde que jamais.

\section{AUTEURS}

\section{CLÉMENT THERME}

Paris 